\title{
Fuzzy expert systems (FES) for halal food additive
}

\author{
M. Zaki Zakaria, Norhana Nordin, Ariff Md Ab Malik, Shamsul J Elias, Ahmad Zambri Shahuddin \\ Faculty of Computer and Mathematical Sciences,University Technology of MARA, Shah Alam, Malaysia
}

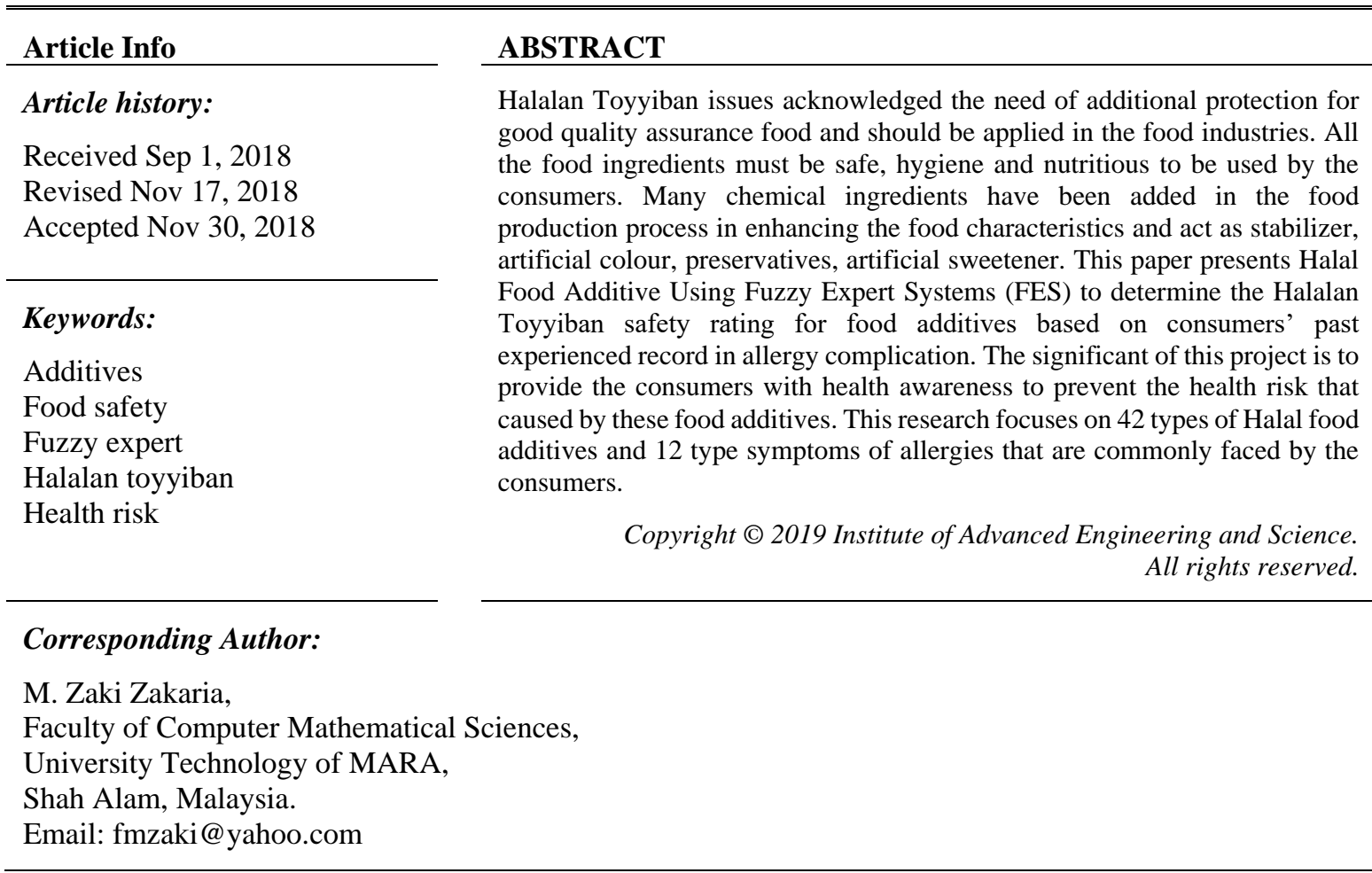

\section{INTRODUCTION}

Halal issues are vital to the Muslims and can be defined as permitted or lawful which covers in many Islam aspects. In the perspective of Muslim food preparation, Department of Standards Malaysia has developed a comprehensive Halal guideline standard for food, MS1500:2009 that covers from production, preparation, handling and storage. The purpose of this guideline is to ensure all permissible food is produced with risk-free and hygienic regards to Syariah law [1].

Currently, there is a need to have an extensive awareness on a wider scope of Halalan Toyyiban concept. This means instead of Halal, there must be a necessity to all Muslims to choose the food that is Toyyiban status. Toyyiban refers to safe, clean, nutritious and quality, and processed food or its ingredients shall be safe for consumption, non-poisonous, non-intoxicating or non-hazardous to human health [2]. By emphasizing on this concept, the quality of the produced food can be ensured and could satisfy the consumers on the usage of these products in fulfilling the consumers' needs and expectation [3, 21].

With the advancement of the food engineering, it has allowed the food industry players to increase the food production $[4,5]$. Thus, these technologies have served customer's demand to enjoy food supply in perspective of storage durability, flavourful, colourful and affordability. However, it has indirectly encouraged the food producers to utilize some harmful chemical elements, such as fertilizers and growth agents that may harm to the human in long term. Most of the food structures have been modified and this can cause negative implication to the human body. The chemicals are added to the food in order to counter food perishability or enhance the colour or flavour in the food [5].

According to $[5,7,8],[11-13]$, there is three main categories of additives; (i) residue chemical, (ii) contaminants chemical, (iii) food additives.

The pesticides or foreign chemicals are the best examples of the first category, which is generally used by food producers and may remain during the final stage of food production [11-13]. Meanwhile, toxin is 
one of the additives elements in the second category [8], [11-13] that may accidentally be contaminated into the food supply either via the food chain, supply chain or own kitchen. Lastly, food preservatives, sweeteners, flavour enhancer, emulsifiers, or dyes are the examples of the final category that had been added into food products in order to increase the properties of the processed food [5, 7, 10, 15]. Commonly, the basic function of food additives is either to create the food looks and tastes better or to make the food safer, by preserving it from bacteria, preventing oxidation or other chemical changes $[6,10]$.

Even though the accountability of assuring the chemical ingredients usage is under the manufacturers' jurisdiction, but other parties such as consumers and the authorities must also proactively play their roles to ensure these ingredients are safe or not harmful to eat [10]. This is because some of the manufacturers may be potentially used unsafe chemical ingredients in their food production which may expose to unwanted diseases to the consumers in the future. The different types of food that available today for the consumers may contain several chemicals that could affect their health [11, 12]. Not only tasteful of food is important, but also the appearance of the food must also look attractive [7]. Without using the food additives as an enhancer function in the food, it would be not impossible to preserve the food appearance and taste but also its durability [5, 7]. Thus, the consumers may expose to hazardous food additives that can bring to chronic allergic reaction or other diseases $[7,9,14]$.

The main problem that leads to this work is most of the food structures have been modified where some of the additive agent have been used to enhance durability or freshness of the food that may cause negative implication to the human body.

These ingredients are still considered unhealthy food agents that can change the originality of food characteristics $[11,12]$. With a large amount intake of this chemical ingredients, it may indirectly contribute to health implication such chronic diseases the consumers in the long run [14]. Besides, food consumers commonly do not know or less knowledge of the safety rating of food additives in the processed food. In addition, each of the consumers may have the different allergy reaction and every food additive may also have different reaction to the human body. Only those who have past experienced with the allergy may only know the consequences of these additives.

The motivation of this work is to turn this food safety-related data into useful information that enable any potential consumers to determine any harmful chemical ingredients in the food is safe to be consumed. Thus, it may help the consumer to make the best decision either to consume the intended food or not. In Islam perspective, this goal can be achieved by fulfilling the criteria of Halalan Toyyiban which reflects the standard and the quality of food ingredients, where the processes of verification and certification of the safeness and healthiness based the food sources can be done [3, 6, 21].

The objective of this research is to develop a Halalan Toyyiban health food additives case-based system that could allow any prospective food consumers to check the possibility of additives' health impacts due to consumers' health past historical on allergy and complication. Through this system, it could also provide assurance of reputable Halal products in good quality without any harmful substances subject to allergy symptoms based on Halal food additives' safety rating mechanism.

This paper presents Halal Food Additive Using Fuzzy Expert Systems (FES). In this study, consumers are cautious on their food consumption which can cause allergy by assessing using fuzzy expert system.

\section{RELATED WORKS}

According to [12] and [15], food additives become a part of the food products when they are added to the food. They are affecting the characteristic of the food when adding directly during food processing for a specific purpose. The additives can also be found during the process of packaging, handling, and storage of food. Without preservatives, bacteria growth may lead to the production of toxin that can cause food poisoning $[6,16]$.

Referring to [17], the usage of dyes in food and cosmetic products will give health effects to the users mainly if these dyes enter the bloodstream through the digestive tract or via the skin. Hence, the respiratory system may not function smoothly and can lead to side effects such as aspiration of gastric, allergies, asthma, hypotension, and blue-tinged skin. Furthermore, [16] emphasized that additives like sulfites, aspartame, parabens, MSG, BHT, and nitrate may also cause the reaction to the human body but still depend on the sensitivity of the consumers to the ingredients and the amount consumed.

This research focuses on Halal food additives used in food packaging, for examples flavour enhancer, stabilizer, emulsifier, antioxidants and artificial colour, and will only concentrated on 42 types of Halal food additives. These food additives, such as acesulfame potassium, adipic acid, alpha-tocopherol, annato, and ascorbic acid, will be grouped into several rating categories either as safe, cut back, caution or harm. Besides that, only 12 type symptoms of allergy, for examples condition of hives, sweat, stomach cramps, vomit, diarrhoea, migraine, numbness, abnormal behaviour, difficulty breathing, cough, joint aches and weakness will 
be used as a main diagnose focus symptoms in this work. Each of the allergy symptoms will be rated subject to the pain scales from allergy or complication experience consumers. These scales will be categorized as no allergy, mild, moderate, severe and intense.

Since the fuzzy model has been widely used in the expertise and observation based on clinical framework of decision support system, fuzzy expert system technique will be utilized in measuring the safety rating and drawing conclusions based on the data [18], [22-25]. Through this system, the knowledge base subject to consumer-allergy complication history will be stored in the database. The inference engine will apply logical rules between the fuzzy graph to the knowledge base and create new knowledge [19], [22], [24, 25]. This process would repeat as each new fact in the knowledge base could trigger additional rules in the inference engine. The inference engines will work fundamentally that divides into two part which are forward chaining and backward chaining. Forward chaining starts with the known facts and claims new facts. Backward chaining starts with goal and work backward to figure out what facts must be asserted so that the goals can be achieved [20].

This project contributes to the knowledge of Halal food additives in the food and research study and will also determine the safeness additives of Halal food of the consumers by calculating their range of allergy condition from the past experienced records. Apparently, the extensive usage of the food additives may bring more harm to human body and can contribute to the problems of miscarriage, birth defects, lung disease and other critical diseases $[11,12,14,17]$. This work will benefit the consumers by providing the status of the food additives based on their symptoms of allergy according to Halalan Toyyiban concept.

\section{FUZZY INFERENCE SYSTEM}

Knowledge representation is fully explored the data collection to construct rule and fact. In this phase, the information was filtered to fulfill the needs of the work and the unrelated one will be removed. Symptoms may be varied from a person to another person, thus in this work, there are only twelve (12) linguistic variables has been applied based on the common symptoms.

A model has been developed for this prototype system to show the elements involved in the development of the system. This model shows that a user needs to provide an input which will be processed by fuzzy inference engine and expert rules. The prototype system model is described in Figure 1.

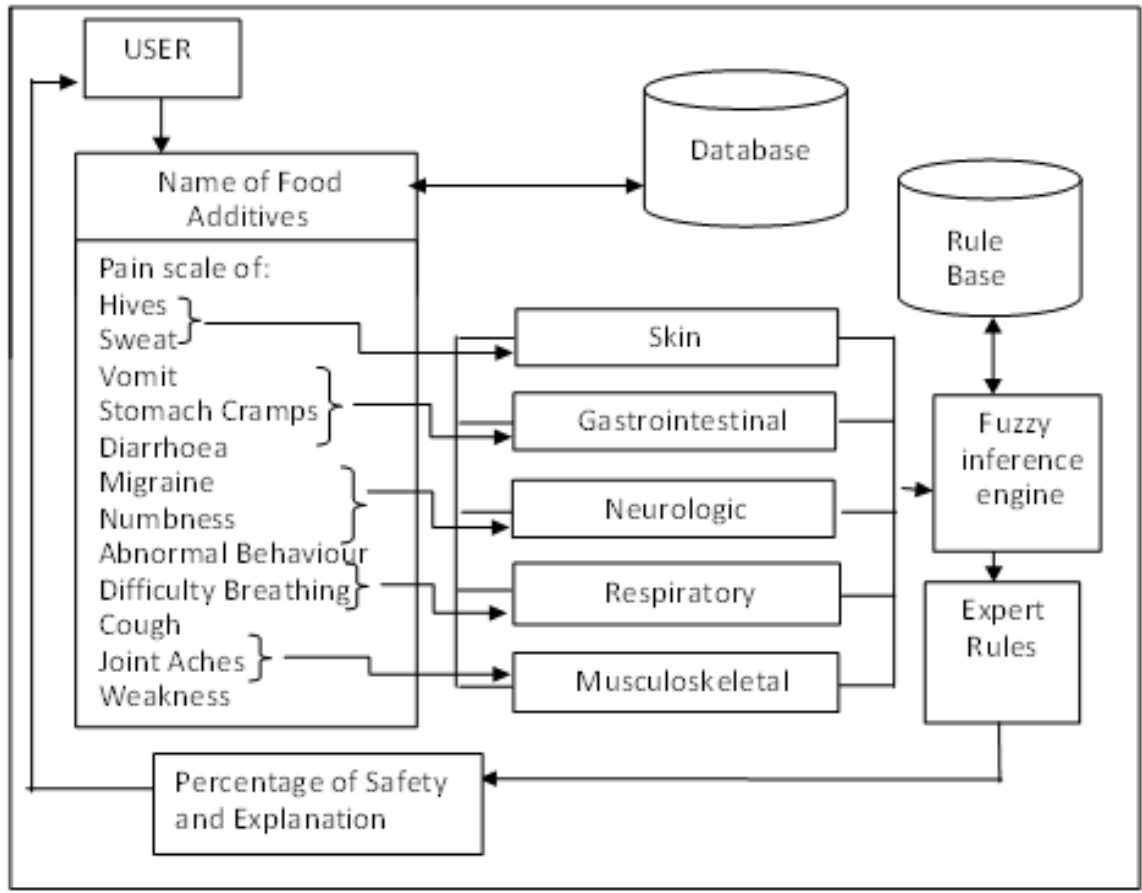

Figure 1. System model that based on 42 types of halal food additives and 12 type symptoms of allergies 


\section{RESULT AND FINDING}

The system is developed to assess the level of body tolerance towards the food additives. The data which are collected for the assessment include the name of food additives and the symptom of the allergies that would be resulted from the intake. Subsequently, the data from user input will be evaluated by the fuzzy expert system and profiled according to the food additive classification and the safety rating (as per Table 1).

The final fuzzy set output graph is determined by the process of fuzzification, rule evaluation, aggregation of output and defuzzification. For examples, the input of hives and sweat fuzzy value are determined by the graph to get the output of skin allergy as shown in Figure 2 and Figure 3.

The inference engine will take the rules that provided by the knowledge base to draw a conclusion by using the internal rules of inference. These components are connected to the fuzzy rule-based system which has the process of fuzzification, inference system that would generate the safety rating from rule-based IF...THEN and process of defuzzification. Figure 4 shows the fuzzy rule-based expert system model in which the user will enter the Halal food additives to identify the safety rate and reason.

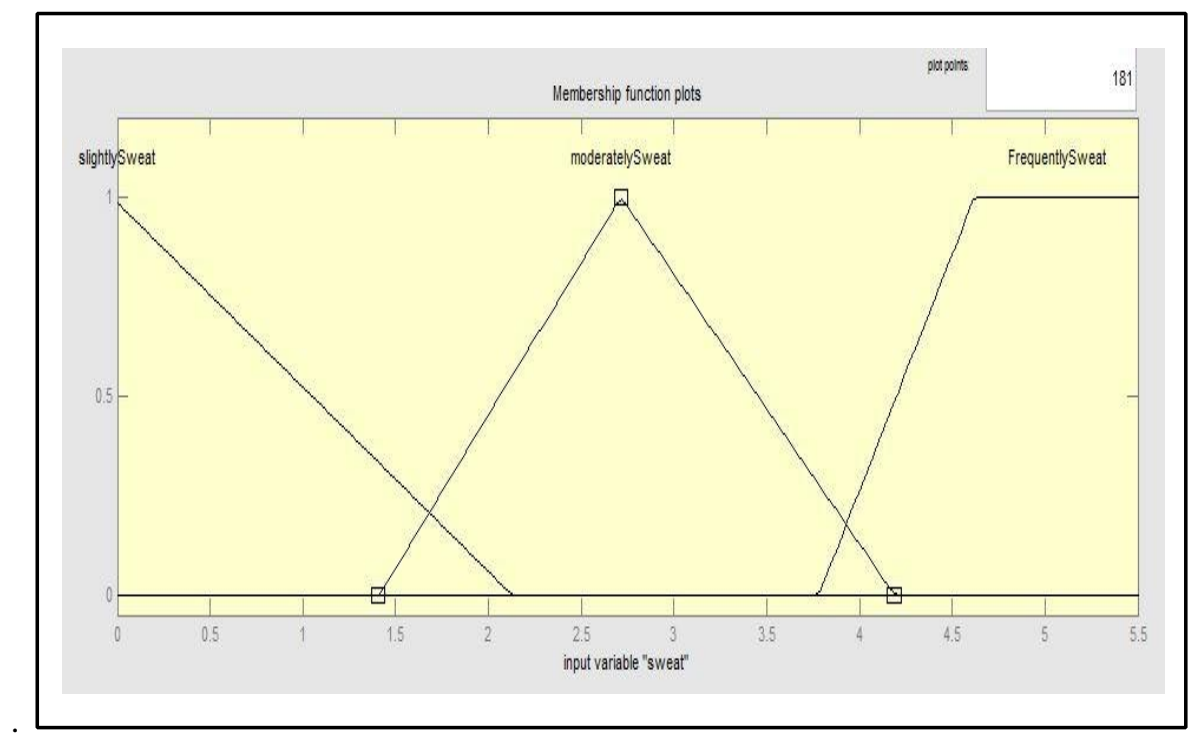

Figure 2. Sweat Graph

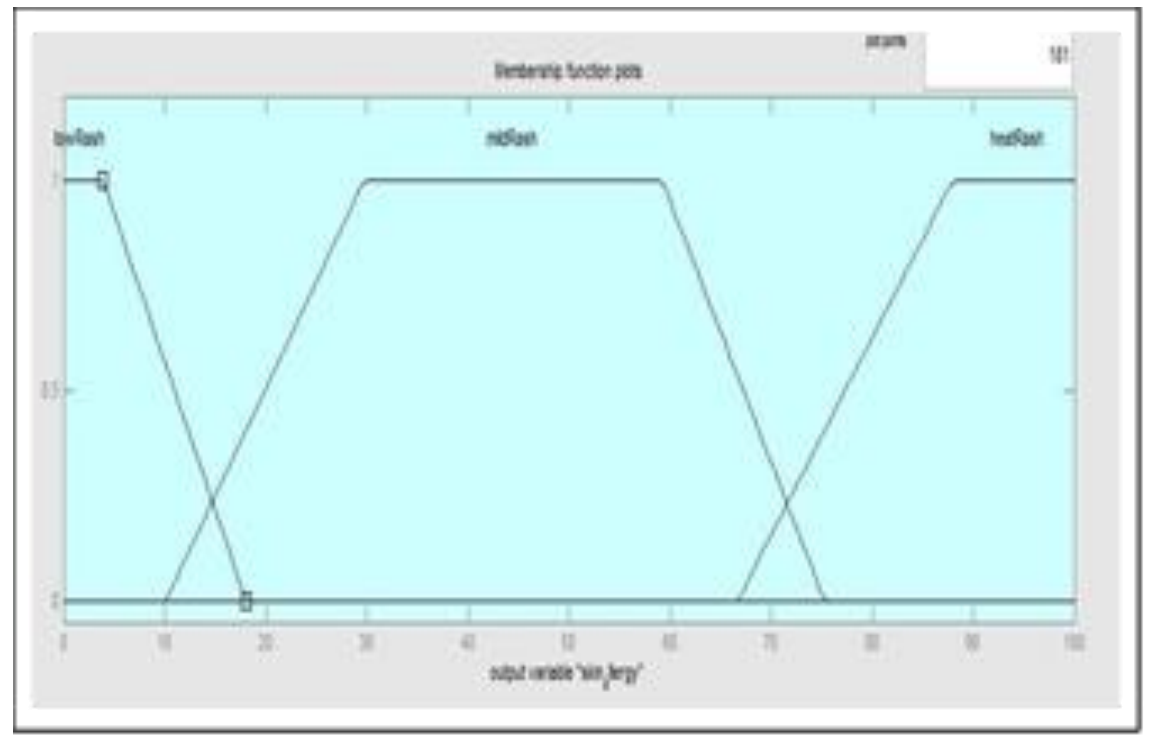

Figure 3. Skin allergy graph 


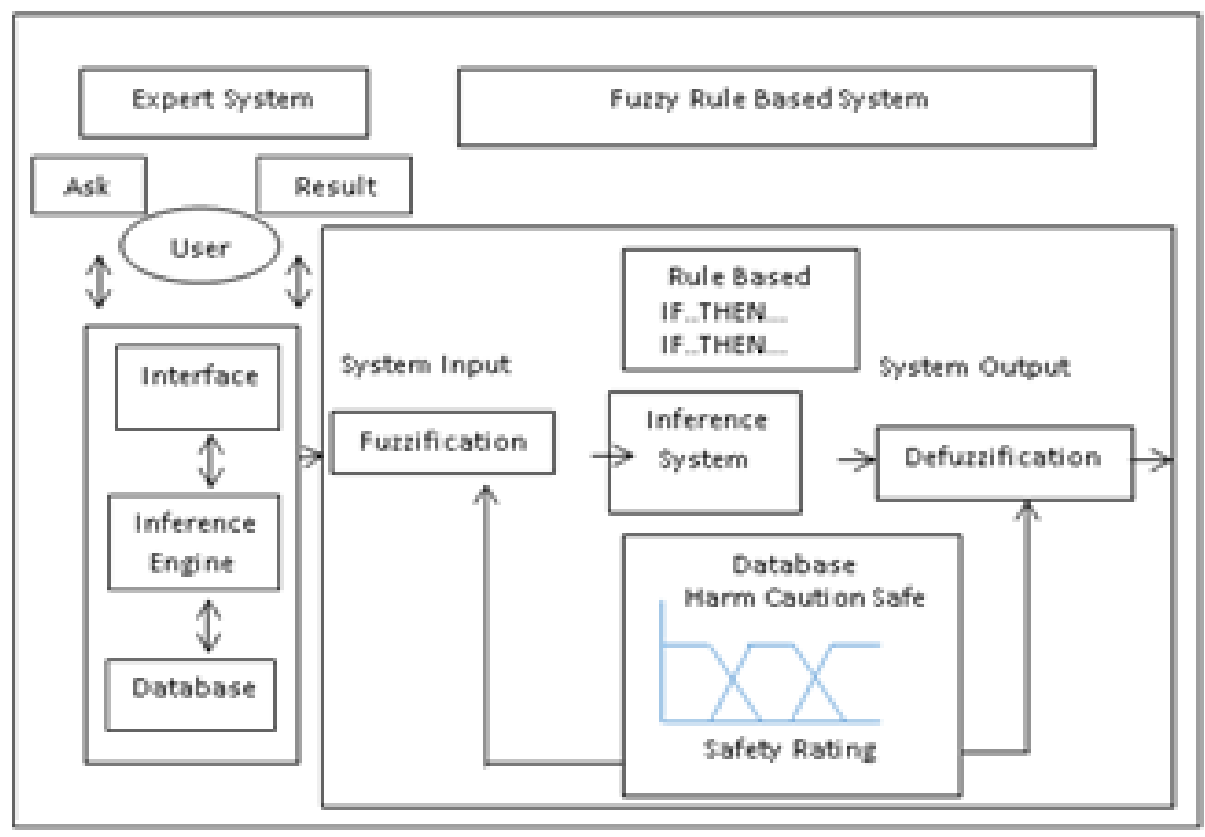

Figure 4. Fuzzy Rule-Based Expert System Model

The first step of fuzzification is to take the types of Halal food additives and crisp input range of condition of their allergies in order to determine the degree to which these inputs belongs to fuzzy set. With the multiple antecedents, AND fuzzy operator is used to obtain a single result that represents the antecedent evaluation. Later, all the values of the pain scale plot in membership function will be clipped and combined into one single fuzzy set. Defuzzification will take place in the last step to be changed into crisp number back in the final output by using Weighted Average (WA) to calculate over a sample of points. All information is organized appropriately in knowledge based that contains the domain knowledge. The knowledge is represented as a set of rules in the expert system and the knowledge based, also known as long-term memory, contains general knowledge belongs to the domain of interest. The safety rating for this problem can be referred as in Table 1.

\begin{tabular}{ll} 
Table 1. Safety rating for food additive classification \\
\cline { 2 - 2 } Food Additive Classification & Safety Rating $(\%)$ \\
\hline Safe & $0-20$ \\
Cut Back & $21-59$ \\
Caution & $60-79$ \\
Harmful & More than 80 \\
\hline
\end{tabular}

\section{CONCLUSION}

This paper has presented Halal Food Additive Using Fuzzy Expert Systems (FES). Halal food additives checker system will provide consumers with a useful result on the safety rating key based on the consumers' past record experience of any food consumed. This project is highly recommended to all health conscious's consumers who care to prevent bad effect to their bodies. It is hoped that this project will be beneficial in helping the consumers to find the nutritious food, in order to maintain or improve their health while meeting Halalan Toyyiban criteria. More details about the food additives need to be explored as to generate better future undertaking improvements.

\section{REFERENCES}

[1] Malaysian Standard, "MS 1500:2009 Halal Food - Production, Preparation, Handling and Storage - General Guidelines." (Second Revision), (2009).

[2] Halal Industry Development Corporation http://www.hdcglobal.com/publisher/cdh_Halalan_Toyyiban (2013) as reviewed 20 Oct 2017. 
[3] N. Elassy, "The concepts of quality, quality assurance and quality enhancement", Quality Assurance in Education, Vol. 23 Issue: 3, pp.250-261, https://doi.org/10.1108/QAE-11-2012-0046, 2012.

[4] M. Pyke, "The future of food engineering. Nutrition \& Food Science", Vol. 77 Issue: 1, pp.5-7, (1977). https://doi.org/10.1108/eb058660. ,2015.

[5] B. N. Koyratty, Shaheen, B. Aumjaud, and S.A. Neeliah, "Food additive control: a survey among selected consumers and manufacturers." British Food Journal, Vol. 116 Issue: 2, pp.353-372, https://doi.org/10.1108/BFJ-05-2012-0125, 2014.

[6] M. Saltmarsh and L. Insall, "Essential Guide to Food Additives." The Royal Society of Chemistry. (4), 1-13, Retrieved from www.rsc.org, 2013.

[7] J. Senker, "Food Ingredients: Retailers' Response to Consumer Concern." British Food Journal. Vol. 92. Issue: 1. pp.11-14, 1990, https://doi.org/10.1108/ 00070709010139319.

[8] J. Wonnacott, "Food Additives. Nutrition \& Food Science", Vol. 86 Issue: 1, pp.20-21, 1986, https://doi.org/10.1108/eb059105.

[9] J. Stevenson, "Food additives and children's behaviour: evidence-based policy at the margins of certainty". Journal of Children's Services, Vol. 4 Issue: 2. pp.4-13, https://doi.org/10.1108/ 17466660200900008, 2009.

[10] J. Cole, "The additives issue. Nutrition \& Food Science", Vol. 86 Issue: 3. pp.26-27, 1986, https://doi.org/10.1108/eb059117.

[11] D. Atkins, “The UK's Food Chemical Surveillance Programme”, British Food Journal, Vol. 96 Issue: 2. pp.24-29, 1994, https://doi.org/10.1108/ 00070709410059116.

[12] D.P. Atkins, and S.M. Smith, "Chemical Safety of Food: MAFF's Role”. British Food Journal, Vol. 91 Issue: 8. pp.15-23, 1989, https://doi.org/10.1108/00070709010133883.

[13] Nutrition \& Food Science. "Food safety issues: Pesticides residues". Nutrition \& Food Science, Vol. 89 Issue: 3. pp.22-23, 1989, https://doi.org/10.1108/eb059236.

[14] T. Knowles, R. Moody, and M.G. McEachern, "European food scares and their impact on EU food policy". British Food Journal, Vol. 109 Issue: 1. pp.43-67, 2007, https://doi.org/10.1108/ 00070700710718507.

[15] A. Turner, "Food Standards, Food Manufacturers and 1992". British Food Journal, Vol. 93 Issue: 7. pp.3-11, 1991, https://doi.org/10.1108/EUM0000000002350.

[16] R.M. Pandey and S.K. Upadhyay, "Food Additive, Food Additive". Prof. Yehia El-Samragy (Ed.). ISBN:978-95351-0067-6, InTech, 2012. Available from: http://www.intechopen.com/books/food-additive/food-additive

[17] M. Lucová, J. Hojerová, S. Pažoureková, and Z. Klimová, “Absorption of triphenylmethane dyes Brilliant Blue and Patent Blue through intact skin, shaven skin and lingual mucosa from daily life products". Food and Chemical Toxicology 52. 19-27. 2013.

[18] S.S. Sikchi, S.ikchi, and M.S. Ali. "Fuzzy Expert Systems (FES) for Medical Diagnosis". International Journal of Computer Applications, 63. 7-16. 2013. DOI: 10.5455/ijmsph.2013.2.56-61.

[19] F. Hayes-Roth, D. Waterman, and D. Lenat, "Building Expert Systems". Addison-Wesley Longman Publishing Co., Inc. Boston, MA, USA. 1983.

[20] N.L. Griffin and F.D. Lewis, "A Rule-Based Inference Engine which is Optimal and VLSI Implementable”. IEEE International Workshop on Tools for Artificial Intelligence. Architectures, Languages and Algorithms, 1989.

[21] M.A. Ab. Halim, K.W. Mohd, M.M.M. Salleh, A. Yalawaed, T.S.M.N.S. Omare, A. Ahmad, A.A. Ahmad, and M.I.A.M. Kashim, "Consumer Protection of Halal Products In Malaysia: A Literature" Highlight. Procedia - Social and Behavioral Sciences 121. 68 - 78, 2014.

[22] K. Goztepe, "Designing a Fuzzy Rule Based Expert System for Cyber Security". International Journal of Information Security Science. Vol 1 No.1, 2012.

[23] S.J. Chen and S.M. Chen, "Fuzzy risk analysis based on the ranking of generalized trapezoidal fuzzy numbers". Applied Intelligence, 26(1), 1-11, 2007, DOI 10.1007/s10489-006-0003-5.

[24] C. Kahraman, S. Cevi, N.Y. Ates and M. Gulbay, "Fuzzy multi-crieria evaluation of industrial robotic systems". (2007) Computer \& Industrial Engineering, 52, 414-433, 2007, doi: 10.1016/j.cie.2007.01.005.

[25] N.Ramli and D. Mohamad, "On the Jaccard index with degree of optimism in ranking fuzzy numbers". In E. H“ullermeier, R. Kruse, and F. Hoffmann (Eds.): IPMU 2010, Part II, CCIS 81,6. Ribière, M., Charlton, P.: Ontology Overview. Motorola Labs, Paris (2002). [Online].(2010). Available: http://www.fipa.org/ docs/input/f-in-00045/f-in00045.pdf (current October 2003) 